\title{
Delayed Treatment Response in a Neonate with Multisystem Langerhans Cell Histiocytosis Case report and review of literature
}

*Amitabh Singh, ${ }^{1}$ Anirban Mandal, ${ }^{2}$ Lavleen Singh, ${ }^{3}$ Sataroopa Mishra, ${ }^{1}$ Ankita Patel ${ }^{1}$

$$
\begin{aligned}
& \text { الإستجابة المتأخرة للعلاج في طفل حديث الولادة مصاب } \\
& \text { بمرض لابكرهانز هيستيوسيتوزيس } \\
& \text { تقرير حالة ومراجعة اللأدبيات }
\end{aligned}
$$

أميتاب سينغ، أنيربان ماندال، لافلين سينغ، ساتاروبا ميشرا، أنكيتا باتيل

ABSTRACT: Langerhans cell histiocytosis $(\mathrm{LCH})$ is a rare proliferative disorder of the Langerhans cells, which are part of the mononuclear phagocytic system. The disorder varies in terms of the extent of the disease, its natural course and patient outcomes. While skin rashes are a common presentation of neonatal $\mathrm{LCH}$, other systems or organs may also be involved. Delays in the diagnosis of neonatal LCH may occur due to its non-specific presentation and a lack of awareness of the condition among doctors. We report a two-month-old male neonate who presented to the Chacha Nehru Bal Chikitsalya hospital, New Delhi, India, in 2016 after the onset of pulmonary symptoms. He had been noted to have a generalised rash which had progressively worsened from 15 days of age. Following a skin biopsy and chest imaging, he was diagnosed with multisystem LCH with risk organ involvement. There was a delayed response to combined chemotherapy with no major side-effects.

Keywords: Langerhans Cell Histiocytosis; Seborrheic Dermatitis; Tachypnea; Anemia; Infant; Case Report; India.

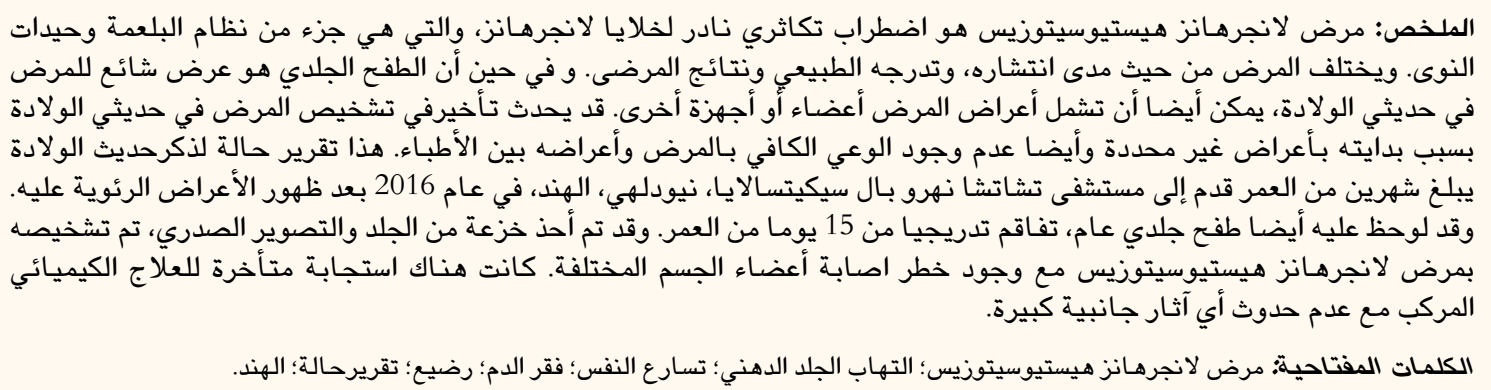

L ANGERHANS CELL HISTIOCYTOSIS (LCH) IS a very rare disease resulting from the clonal proliferation of Langerhans cells in the mononuclear phagocytic system. ${ }^{1}$ The disorder can occur at any age and may be either completely benign and self-resolving or fatal and refractory. Clinically, the presentation varies depending on whether the patient has single-system (i.e. involvement of only one organ or system) or multisystem (i.e. involvement of two or more organs or systems) LCH. ${ }^{1}$ The involvement of the liver, spleen, bone marrow or lungs is classified as risk organ (RO) involvement, as this may adversely affect patient outcomes. ${ }^{2}$

Neonatal LCH is believed to be under-reported with an incidence of slightly over 1 per million newborns. ${ }^{3}$ Nearly all cases present within the first four weeks of life, most commonly with singlesystem LCH with spontaneous remission (also known as Hashimoto-Pritzker disease or congenital selfhealing LCH). ${ }^{4}$ However, a thorough investigation of most single-system neonatal LCH cases will show involvement other sites; moreover, multisystem LCH in neonates has a less favourable prognosis compared to those of other age groups. ${ }^{3}$ Similarly to older children, the optimal treatment option for infants with LCH is combination chemotherapy as per the 2009 Histiocyte Society guidelines for $\mathrm{LCH}$ evaluation and treatment. ${ }^{2}$ This report describes a case of neonatal multisystem LCH with RO involvement treated successfully with combined chemotherapy as per the 2009 Histiocyte Society guidelines. ${ }^{2}$ 


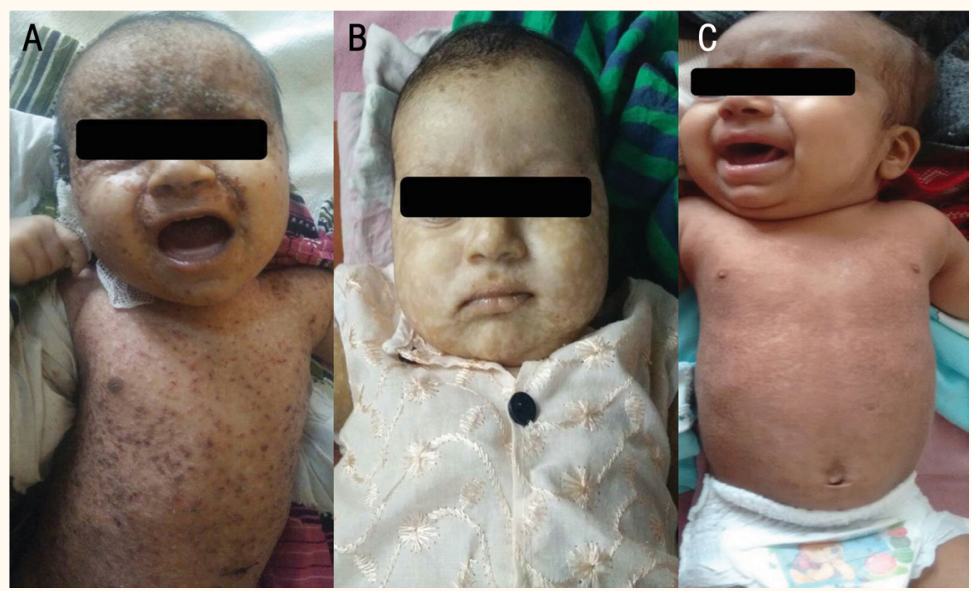

Figure 1: Photographs of a two-month-old male neonate (A) at presentation, with extensive papulonodular lesions and crusting over the whole body and a seborrhoea-like rash over the scalp, (B) after six weeks of chemotherapy, with limited resolution of the lesions and hypopigmented macules, and $(\mathbf{C})$ after six months of therapy, with very few remaining hyperpigmented lesions and fine scaling.

\section{Case Report}

A two-month old male neonate presented to the Chacha Nehru Bal Chikitsalya hospital, New Delhi, India, in 2016 with tachypnoea over the past seven days and a progressive generalised rash of one and a half months' duration. The baby was the first child of nonconsanguineous healthy parents. The antenatal course had been uneventful and he was born at term via normal vaginal delivery. At birth, he weighed $3.4 \mathrm{~kg}$ with no adverse perinatal events. The neonate was breastfed exclusively. Shortly after birth, the mother noted a rash on the infant's scalp which rapidly spread over the whole body over the next 15 days. Initially, the baby was treated for cradle cap after consultation with a paediatrician; however, as the skin lesions increased, he was referred to a dermatologist who diagnosed him with extensive seborrhoeic dermatitis. Topical medications were prescribed but were ineffective. There was no medical history of fever, coughing, lethargy, poor feeding, cyanosis, jaundice, abdominal distention, vomiting, loose stools, seizures or bleeding. However, there was a history of ear discharge and increased urine output.

At presentation, the child had tachypnoea and mild chest retractions but maintained normal oxygenation in room air. There were extensive papulonodular lesions with crusting over his whole body, although the mucosal surfaces were unaffected [Figure 1A]. There was no evidence of pallor, icterus or lymphadenopathy. A systemic examination revealed hepatomegaly and fine crepitations in both sides of the chest. Blood test results revealed mild microcytic hypochromic anaemia and hepatitis [Table 1]. A peripheral smear showed microcytic hypochromic red blood cells with anisopoikilocytosis and no abnormal cells. Bilateral diffuse lung parenchymal opacities with cysts were observed on a chest X-ray, with computed tomography $(\mathrm{CT})$ confirming the presence of diffuse cystic lesions in both lungs [Figure 2]. An ultrasound of the liver indicated a heterogeneous echotexture with peri-portal echogenicity. A skin biopsy revealed

Table 1: Blood investigation results of a two-monthold male neonate with pulmonary symptoms and a generalised whole-body rash

$\begin{array}{lc}\text { Investigation } & \text { Result } \\ \text { Hb in gm/dL } & 10.5 \\ \text { WBC per mm3 } & 10,600 \\ \text { Neutrophils in \% } & 76 \\ \text { Lymphocytes in \% } & 19 \\ \text { Monocytes in \% } & 4 \\ \text { Eosinophils in \% } & 1 \\ \text { Platelet count per mm }{ }^{3} & 301 \times 10^{3} \\ \text { Total bilirubin in g/dL } & 0.9 \\ \text { Conjugated bilirubin in g/dL } & 0.4 \\ \text { AST in U/L } & 115 \\ \text { ALT in U/L } & 213 \\ \text { Total protein in g/dL } & 5.9 \\ \text { Albumin in g/dL } & 3.5 \\ \text { ALP in U/L } & 81 \\ \text { GGT in U/L } & 115 \\ \text { Urea in mg/dL } & 28 \\ \text { Creatinine in mg/dL } & 0.3\end{array}$

$H b=$ haemoglobin $; W B C=$ total leukocyte count $; A S T=$ aspartate transaminase; $A L T=$ alanine transaminase $A L P=$ alkaline phosphatase; GGT = gamma glutamyl transferase. 


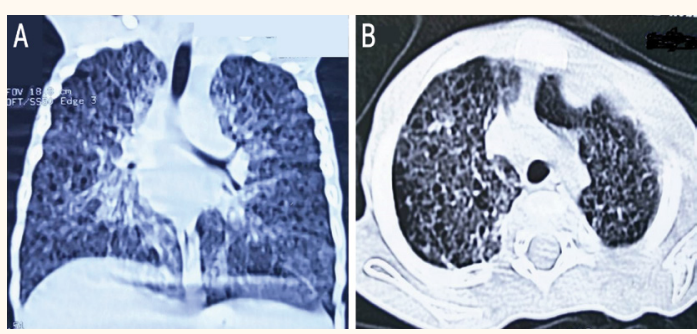

Figure 2: A: Chest X-ray of a two-month-old male neonate with pulmonary symptoms and a generalised whole-body rash showing bilateral diffuse lung parenchymal opacities with cysts. B: Computed tomography in the chest axial view showing cysts of variable sizes involving both lungs.

infiltration by Langerhans cells with cluster of differentiation (CD) 1a positivity, confirming the diagnosis of LCH [Figure 3]. A skeletal survey, bone marrow examination and brain magnetic resonance imaging ruled out any skeletal, bone marrow or central nervous system involvement.

Following the diagnosis, the neonate was treated with daily prednisolone and weekly vinblastine at modified doses as per the 2009 Histiocyte Society guidelines. ${ }^{2}$ However, although the lesions began to atrophy and depigment after six weeks, new lesions began to appear, some of which were deeply ulcerated [Figure 1B]. Due to worsening dyspnoea, the child was admitted to hospital as an inpatient for monitoring. As he had demonstrated an incomplete response to the initial treatment, prednisolone and vinblastine were continued for another six weeks. Following this, positron emission tomography/computed tomography indicated that the disease was non-active [Figure 4]; as such, continuation therapy was initiated. At the time of writing, after a total of six months of therapy, the child was asymptomatic and appeared to be thriving. The pneumatoceles had disappeared completely, with only a few hyperpigmented skin lesions remaining [Figure 1C]. As per the 2009 Histiocyte Society guidelines, another 12 months of treatment were subsequently planned. ${ }^{2}$

\section{Discussion}

The differential diagnosis of a neonatal skin rash includes congenital infections (e.g. cytomegalovirus, rubella, toxoplasma, herpes simplex virus or syphilis infections), seborrhoeic dermatitis, LCH, disseminated candidiasis, neonatal varicella, neonatal pustular melanosis and mastocytosis. ${ }^{1,5}$ This report describes a case of neonatal multisystem LCH with $\mathrm{RO}$ involvement which was initially misdiagnosed as seborrhoeic dermatitis and only accurately diagnosed following the onset of pulmonary symptoms. Although the presentation in this case was similar to other cases described in the literature, there was a delay of approximately one and a half months before the correct diagnosis was established. ${ }^{3,4}$ According to data from a European LCH study group, only $32.7 \%$ of neonatal LCH cases were diagnosed during the neonatal period. ${ }^{3}$ In an American cohort, the mean age at diagnosis was three and a half months for neonatal LCH cases, with initial misdiagnoses often including psoriasis and chronic dermatitis. ${ }^{6}$

As the type and characteristics of skin lesions in neonatal LCH are not predictive of the extent of disease involvement, a thorough multiorgan evaluation is indicated for all patients. ${ }^{67}$ Data from a European LCH study group indicated that most neonatal LCH cases had multisystem involvement (59\%), with skin lesions being the most common initial presentation; in addition, 5.5\% of multisystem cases had dyspnoea. ${ }^{3}$ As such, dyspnoea secondary to lung involvement could indicate an advanced disease state, as seen in the present case. Park et al. reported that skin lesions were also the most common initial presentation among six neonatal LCH cases in Korea (83.3\%). ${ }^{7}$ In a case series of 19 neonatal LCH patients with dermatological presentations in the USA, Stein et al. noted that $68 \%$ were male and $63 \%$ had multisystem involvement. ${ }^{6}$ The most common skin lesions observed were erythematous vesicopustules
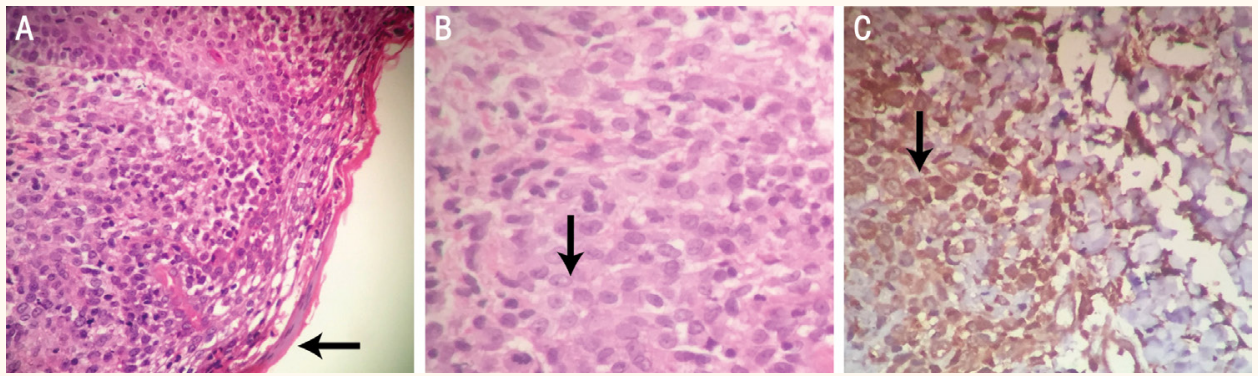

Figure 3: A: Haematoxylin and eosin (H\&E) stain of a punch biopsy at x200 magnification showing diffuse replacement of the superficial dermis by enlarged mononuclear cells (arrow). B: H\&E stain at x400 magnification showing mononuclear cells with abundant eosinophilic cytoplasm and kidney-shaped grooved folded nuclei (arrow) and fine vesicular chromatin and inconspicuous nucleoli. C: Immunohistochemistry stain at x400 magnification showing neoplastic Langerhans cells immunopositive for cluster of differentiation 1a (arrow). 

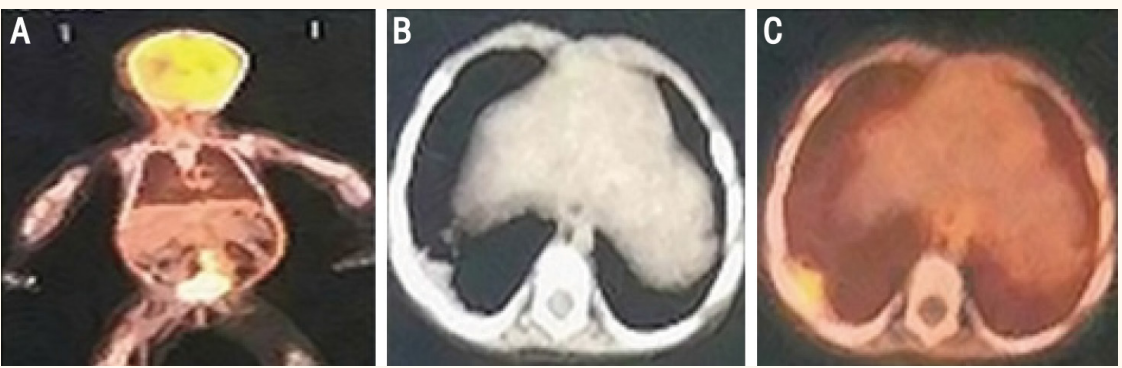

Figure 4: Positron emission tomography/computed tomography showing no metabolically active disease in a twomonth-old male neonate presenting with pulmonary symptoms and a generalised whole-body rash following 12 weeks of treatment for multisystem Langerhans cell histiocytosis.

(53\%), often with crusting, followed by eczematous scaling lesions in a seborrhoea-like distribution (37\%) and oral mucosal lesions $(20 \%){ }^{6}$ In contrast, the present patient had a seborrhoea-like skin rash without any mucosal involvement.

An accurate diagnosis of $\mathrm{LCH}$ requires either a histopathological examination of the involved tissue to demonstrate the presence of pathognomonic CD1a- and/or CD207-positive Langerhans cells or an electron microscopy study to identify Birbeck granules. ${ }^{1}$ However, a recent case report by Kumar et al. suggests that fine-needle aspiration cytology may also be effective in diagnosing $\mathrm{LCH}$, alleviating the need for an invasive biopsy. ${ }^{8}$ Lung involvement in LCH has a variable appearance on chest CT scans, ranging from small peribronchiolar nodular opacities to multiple irregularly-shaped cysts. ${ }^{1}$ In the current case, the CT findings were pathognomonic, showing cysts of variable size in both lungs.

While a few cases of multisystem LCH have been reported to resolve spontaneously, this is very rare; only $8 \%$ of multisystem $\mathrm{LCH}$ cases reported by the European $\mathrm{LCH}$ study group, all without $\mathrm{RO}$ involvement, experienced complete resolution without systemic therapy and the five-year survival rate for multisystem $\mathrm{LCH}$ cases was $57 \% .^{3}$ Among the six Korean neonatal LCH cases, the probability of survival at 12 years was $50 \%{ }^{7}$ In an American cohort, survival was $16 \%$ with a variable follow-up period. ${ }^{6}$

Combination chemotherapy is the first line of treatment for $\mathrm{LCH}$ cases. ${ }^{2}$ The reactivation rate falls from $54 \%$ to $37 \%$ after treatment is prolonged from six to 12 months. ${ }^{9}$ However, patients frequently develop various disease- and treatment-related complications, including diabetes insipidus, hearing impairments and liver fibrosis; as such, it is recommended that all patients be monitored for at least five years after the end of therapy for related complications and disease recurrence. ${ }^{1}$

\section{Conclusion}

This report describes a case of neonatal multisystem $\mathrm{LCH}$ with $\mathrm{RO}$ involvement. In order to avoid a delayed diagnosis of neonatal $\mathrm{LCH}$, paediatricians should become more familiar with this rare disorder. In addition, a thorough multiorgan evaluation is warranted in all cases of neonatal $\mathrm{LCH}$ with cutaneous presentations in order to rule out $\mathrm{RO}$ involvement. Use of the 2009 Histiocyte Society guidelines is recommended for the successful management of infants with $\mathrm{LCH}$

\section{References}

1. Haupt R, Minkov M, Astigarraga I, Schäfer E, Nanduri V, Jubran R, et al. Langerhans cell histiocytosis ( $\mathrm{LCH}$ ): Guidelines for diagnosis, clinical work-up, and treatment for patients till the age of 18 years. Pediatr Blood Cancer 2013; 60:175-84. doi: $10.1002 /$ pbc. 24367

2. Histiocyte Society. Histiocyte Society evaluation and treatment guidelines: April 2009. From: www.histiocytesociety.org/docu ment.doc?id=290 Accessed: Feb 2017

3. Minkov $M$, Prosch $H$, Steiner $M$, Grois N, Pötschger U, Kaatsch P, et al. Langerhans cell histiocytosis in neonates. Pediatr Blood Cancer 2005; 45:802-7. doi: 10.1002/pbc.20362.

4. Aggarwal V, Seth A, Jain M, Krishnamurthy S, Chandra V, Aneja S. Congenital Langerhans cell histiocytosis with skin and lung involvement: Spontaneous regression. Indian J Pediatr 2010; 77:811-12. doi: 10.1007/s12098-010-0104-3.

5. Nunley KS, Crone K, Bayliss SI, Vachharajani A. Newborn who has a diffuse rash. Neoreviews 2007; 8:e448-51. doi: 10.1542/ neo.8-10-e448.

6. Stein SL, Paller AS, Haut PR, Mancini AJ. Langerhans cell histiocytosis presenting in the neonatal period: A retrospective case series. Arch Pediatr Adolesc Med 2001; 155:778-83. doi: 10.1001/archpedi.155.7.778.

7. Park YR, Yeo MS, Kim SY, Kim HJ, Koh KN, Im HJ, et al. Langerhans cell histiocytosis diagnosed at the neonatal period. Clin Pediatr Hematol Oncol 2011; 18:92-6.

8. Kumar N, Sayed S, Vinayak S. Diagnosis of Langerhans cell histiocytosis on fine needle aspiration cytology: A case report and review of the cytology literature. Patholog Res Int 2011; 2011:439518 doi: $10.4061 / 2011 / 439518$

9. Gadner H, Minkov M, Grois N, Pötschger U, Thiem E, Aricò M, et al. Therapy prolongation improves outcome in multisystem Langerhans cell histiocytosis. Blood 2013; 121:5006-14. doi: 10.1182/blood-2012-09-455774 